\title{
Empoderamento feminino e trajetória de vida: os modelos rígidos do "ser mulher"
}

\section{Camila Carolina Hildebrand Galetti ${ }^{1}$}

Resumo: Diversos enfoques teóricos e metodológicos marcam os estudos de gênero. Um deles diz respeito às potencialidades do conceito para entender e analisar as memórias e as trajetórias individuais. Conforme pontuado por Rachel Soihet (2009), a abordagem biográfica permite situar no centro da problemática a experiência social das mulheres, "não como uma essência qualquer que nos confiaria um segredo de uma identidade feminina hipostasiada", mas com o movimento de um perpétuo e incessante "vai e vem, entre o dado e vivido, o objetivo e o subjetivo, as determinações e as margens de manobra". Esse artigo tem como objetivo através de entrevistas realizadas com a professora da rede pública e aluna de mestrado, mostrar como se deu sua formação em Ciências Sociais, a sua formação como mulher, durante a graduação, evidenciamos as dificuldades vivenciadas, tendo como fio condutor o casamento, a maternidade e a escolarização, numa perspectiva de gênero.

Palavras-chave: Ciências Sociais; Gênero; Trajetória.

Abstract: Several theoretical and methodological approaches mark gender studies. One relates to the potential of the concept to understand and analyze the memories and individual trajectories. As punctuated by Rachel Soihet (2009), the biographical approach allows us to place the

\footnotetext{
${ }^{1}$ Graduanda em Ciências Sociais pela Universidade Estadual de Maringá (UEM); Bolsista do Programa institucional de bolsa de Iniciação à Docência (Pibid).
} 
center of the problematic social experience of women," not as an essence that we trust anyone secret of a female identity hypostatized ", but with the movement of a perpetual and incessant " coming and going between the die and lived, the objective and subjective determinations and the room for maneuver." This article aims through interviews with the teacher in public and master's degree student, showing how was your training in social sciences, his training as a woman, during graduation, we noted the difficulties experienced, having as the thread marriage, motherhood and schooling, a gender perspective. Keywords : Social Sciences, Gender; Trajectory .

\section{Introdução}

A educação das mulheres no Brasil é um fato recente. Devido à posição que as mulheres ocupavam na sociedade, a reclusão dentro do lar e o papel que era atribuído a elas, não permitiam que as mulheres tivessem acesso as escolas, muito menos a graduação. No início da Primeira República o positivismo teve muita influência, quer no governo, quer entre militares, em muitos círculos intelectuais e essa ideologia incitou que as mulheres fossem às escolas, estudassem, pois assim elas formariam homens inteligentes para a "nação" brasileira. Com isso, muitas mulheres começaram a estudar, se tornaram professoras e o magistério tornou-se uma profissão majoritariamente feminina.

As mulheres só conseguiram romper as barreiras legais a respeito da educação e da segregação sexual - pois havia escolas específicas para as mulheres, nas quais os conteúdos ensinados eram 
totalmente guiados pela ideia de que a mulher tem como função social cuidar do lar e dos filhos; e escolas masculinas - em 1971 com a Lei de Diretrizes e Bases da Educação (LDB), que atribuiu equivalência entre os cursos secundários. A partir dai o curso normal secundário passou a ser frequentado intensamente por mulheres, o que possibilitou também a entrada dessas na educação superior. Várias amarras referentes à educação formal e pública das mulheres foram sendo rompidas no transcorrer da história. Com o passar do tempo, a educação se tornou uma ferramenta de empoderamento para muitas mulheres, como é o caso da professora Eliane a qual através de sua trajetória de vida, podemos identificar a diferença que a educação faz na vida das mulheres. E porque não a educação pode se tornar uma ferramenta emancipatória?

Logo que conheci Eliane, percebi que deveria entrevistá-la. Negra, solteira, mãe de uma adolescente e de um menino, foi companheira de um homem durante 10 anos, sem ter casado na Igreja ou no civil. Abriu mão de muita coisa por conta dessa união e após ter acabado esse 'casamento', o curso de graduação que antes era um sonho inatingível, se tornou realidade. Mas para que isso acontecesse, ela teve que conciliar trabalho e dois filhos que, na época, eram pequenos. Após se formar, tornou-se professora da rede pública, e ela é do tipo de pessoa que busca compreender qual é o papel da escolarização na vida das mulheres, ver o antes e o depois de um curso universitário, 
mestrado, doutorado e etc. A trajetória da Eliane, sem dúvida é muita rica e perpassa por muitas questões as quais dizem respeito como a sociedade na qual estamos inseridas/os possui características do padrão familiar patriarcal, da dificuldade de romper com esse modelo. Muitas mulheres encontram dificuldades para se inserirem no mercado de trabalho ou muitas vezes serem aceitas pelos seus próprios familiares por fazerem escolhas que questionam esse modelo no qual oprime as mulheres e atribui a elas valores relacionados ao lar, casamento, família, filho e suas vidas passam a girar em torno dessas questões.

Fica evidente que a trajetória de vida dos indivíduos é cheia de histórias que pode deixar claro que alguns padrões socialmente construídos, que parecem que já foram superados, ainda podem estar vigentes. Por exemplo, quando se decide contar a experiência de vida de uma mulher, negra, que após o término de um casamento se sente liberta e impulsionada a voltar aos estudos, em cursar uma faculdade, mesmo com dois filhos e com todas as dificuldades financeiras, percebemos que essa mesma mulher é julgada por querer desempenhar um papel que para muitos ainda não é visto como um espaço no qual a mulher pode ocupar quando se tem dois filhos para criar e sustentar.

O percurso de uma pessoa ao escolher um curso de graduação passa por várias etapas. Tem o antes, o durante e o após estar formada. Principalmente quando se é mulher, separada e se tem uma filha e um filho para criar sozinha, esses são fatores que dificultam que uma 
pessoa se dedique a uma graduação e na maioria das vezes é o principal motivo para muitas pessoas não fazer um curso superior, pois possuem uma família constituída e precisam arcar com as despesas da casa, dos/as filhos/as. Nesse texto buscarei mostrar como uma professora de sociologia se percebeu como mulher e o impacto que o curso de Ciências Sociais teve em sua vida, sob o foco de gênero. Através da trajetória da Eliane Oliveira buscarei mostrar que a afirmação de Simone de Beavouir em seu livro Segundo Sexo (1967) "Não se nasce mulher, torna-se", é uma afirmativa que faz muito sentido, e o fato de se perceber como mulher faz toda a diferença na vida de uma pessoa.

As trajetórias de vida são histórias ricas, pode nos dizer muito sobre uma determinada sociedade e mostrar que muitos costumes ou modelos ainda estão presentes, não foram totalmente superados, continuam atuando de maneira velada. Para Bourdieu (1996, p.183), a noção de trajetória "conduz a uma série de posições sucessivamente ocupadas por um mesmo agente (ou um mesmo grupo) num espaço que é ele próprio um devir, estando sujeito a incessantes transformações", ou seja, uma história de vida não é uma linha reta, muito pelo contrário, não tem um padrão, é cheia de altos e baixos e oscila conforme os fatos vão se dando.

Diversos enfoques teóricos e metodológicos marcam os estudos de gênero. Um deles diz respeito às potencialidades do conceito para entender e analisar as memórias e as trajetórias individuais, de maneira 
a descortinar o universo social, cultural e político das experiências de mulheres. Conforme pontuado por Rachel Soihet (2009, p.47), a abordagem biográfica permite situar no centro da problemática a experiência social das mulheres, "não como uma essência qualquer que nos confiaria um segredo de uma identidade feminina hipostasiada", mas com o movimento de um perpétuo e incessante "vai e vem, entre o dado e vivido, o objetivo e o subjetivo, as determinações e as margens de manobra", de maneira que neste social e nas estratégias individuais, insere-se um "projeto e que constrói e reconstrói sem cessar o universo social no qual se afirmam, enquanto sujeitos, os indivíduos e os coletivos".

Essa perspectiva permitiria ultrapassar a "dicotomia submissão/rebeldia" e compreender porque "os binômios entusiasmo/ decepção de si/resignação, desvio/conformismo etc, segundo Rachel Soheit (2009), apresentam-se tão próximos nos escritos e nas vidas das mulheres sobre as quais se trabalha".

Para entender o que é se tornar mulher, precisamos compreender a pressão exercida pelo patriarcado sobre as mulheres até os dias de hoje e de como isso pode ser fator decisivo na forma pela qual a maior parte da sociedade enxerga as mulheres e suas relações, principalmente no que diz respeito ao casamento, maternidade e escolarização.

Apesar dos avanços tidos na concepção do que é ser mulher, dos espaços que as mulheres ocupam na sociedade, o papel de esposa, ou 
melhor, de boa esposa, é quesito fundamental para se distinguir se a mulher tem desempenhado seu papel de forma plena - isso em uma concepção patriarcal, machista, que infelizmente a sociedade ainda reproduz e reflete em uma das principais bandeiras de luta das feministas: o fim do patriarcado e do machismo. Para Marillyn Yalom (2002) os papéis sociais de esposa estão diretamente vinculados aos conceitos de casamento e família, os quais são históricos, culturais e políticos. Em outras palavras, em algumas sociedades e culturas são desenvolvidos mecanismos sociais e políticos para transformar as mulheres em esposas "ideais", as quais são desenhadas e fabricadas nas e pelas relações de gênero.

Nessas relações, o cuidado com os filhos, os afazeres domésticos vem em primeiro lugar. Se a mulher desempenha de forma plena essas funções, ela pode se inserir em outros espaços, como trabalhar, fazer uma faculdade e etc. Mulheres que colocam em primeiro lugar suas realizações pessoais, são mal vistas por muitas pessoas que reproduzem o machismo, é como se ela não tivesse o direito de ter vontades, sonhos, ambições e que sua função de ser uma boa dona de casa e mãe são os principais quesitos esperados delas.

Outro aspecto que chama atenção é o impacto que a educação, a escolarização causa na vida e nas relações de muitas mulheres, a educação pode se tornar uma ferramenta de emancipação, pois esse 
quesito pode desencadear vários outros fatores que faça das mulheres, indivíduos mais independentes.

Tendo em vista os aspectos levantados, através de entrevistas com a professora da rede pública e aluna de mestrado, buscarei mostrar como se deu sua formação em Ciências Sociais, a sua formação como mulher, no durante e após a graduação, evidenciamos as dificuldades vivenciadas, tendo como fio condutor o casamento, a maternidade e a escolarização, numa perspectiva de gênero.

\subsection{Trajetória de vida: a ruptura de um modelo de "ser mulher"}

Eliane, 40 anos, negra, mãe de uma menina e um menino, separada, formada em Ciências Sociais, foi professora da rede pública durante 1 ano e 3 meses, atualmente é bolsista do programa de mestrado, estuda sociologia da educação. $\mathrm{Na}$ primeira entrevista realizada com ela, a sua fala inicial é: "Nunca quis me casar, como de fato nunca me casei no civil e na Igreja. Para mim, até hoje vestido de noiva e alegoria de carnaval são a mesma coisa". Essa associação deixa claro que para ela, o ritual do casamento na Igreja conforme os padrões socialmente construídos é algo vago e sem importância.

Antes de ela ter um conhecimento mais acadêmico, se achava 'estranha', pois foi criada para casar, ter filhos, ser dona de casa, conforme os padrões tradicionais, de família, mas não seguiu esses 
preceitos. Apaixonou-se, foi morar com seu companheiro em Fortaleza (CE), teve uma filha e um filho. Ela tinha 19 anos quando resolveu juntar-se ao seu companheiro. Ela menciona que passou 8 anos de sua vida, sendo "mulher do marido", cuidava da alimentação dos filhos, do marido, da casa, é como se ela tivesse se anulado e passado a viver para os outros - seu maridos e filhos. Eles se conheceram em Maringá, mas como a família dele era de Fortaleza, eles se mudaram. Primeiro para Fortaleza, depois para Sobral (CE). Eliane abriu mão de ficar perto de sua família no Paraná, para viver em outro estado perto da família de seu marido.

Segundo ela, o Nordeste é muito influenciado pela religiosidade, devotos de São Francisco, e o machismo é candente em pleno século XXI. O papel da mulher é muito limitado e definido no estilo patriarcal. Quando Eliane se separou, ela ouviu diversas coisas a respeito de seu papel de mulher no seu casamento, pois mesmo que seu excompanheiro havia a traído, muitas pessoas questionaram sua conduta como esposa, como se ele não tivesse desempenhado bem sua função de mulher e tivesse o dever de ter feito alguma coisa para segurar o casamento, o marido. Esse discurso ela ouviu no Ceará e ouviu no Paraná também.

Quando retornou à Maringá, sua mãe a disse que não tinha como se posicionar a favor de sua filha, pois ela não sabia o que ela tinha feito no casamento, ou deixado de fazer para que seu marido chegar ao ponto 
de arrumar outra mulher dentro do casamento. Com isso, percebemos que a mulher é pressionada o tempo todo em suas relações, principalmente dentro da estrutura familiar. Sua mãe reflete o que a sociedade impôs a ela, reproduz o ideário do patriarcado, que a mulher deve servir o seu marido e ser uma boa esposa e dona de casa, pois sendo assim seu marido não terá motivos para procurar outras mulheres. Caso ele procure, isso significa que sua esposa falhou em algum momento, não desempenhou bem seu papel de mulher no casamento.

$\mathrm{Na}$ concepção da Eliane, quando ela se separou parece que resgatou todo um ideal da juventude de escolarização e considera que foi por conta do divórcio que deu o "ponta pé" inicial para a vida acadêmica. Percebeu que a construção de família na qual ela estava inserida, era totalmente tradicional e não queria isso para ela. Queria viver a vida dela independente de qualquer laço tradicional familiar. Quando saiu do casamento, retomou as rédeas de sua vida, voltou a fazer planos e correr atrás deles.

Após retornar à Maringá uma nova fase iniciou em sua vida. Tornou-se uma chefa de família, pois seu marido havia ficado no Ceará e o contato com seus filhos era quase nulo, sem contar que não pode contar financeiramente com a ajuda do mesmo, tendo que trabalhar para sustentar sua filha e seu filho que ainda eram pequenos quando ela se separou. Mesmo com as dificuldades financeiras, ela resolveu prestar vestibular e estudar. Passou em Ciências Sociais na Universidade 
Estadual de Maringá e foi desafiada a dar conta de cuidar dos dois filhos, da faculdade e do emprego.

Quando ela entrou na graduação seus filhos eram novos, tinham 4 e 5 anos. Durante o dia ela trabalhava e seus filhos ficavam na creche o dia inteiro. No período da noite, ela ia para a faculdade enquanto os seus filhos ficavam na casa da avó, pois ela cuidava dos netos todas as noites para que a Eliane pudesse estudar. Talvez se ela tivesse outra percepção de mundo isso seria mais complicado, ficar longe dos filhos durante o dia e a noite para trabalhar e estudar seria algo inaceitável, pois não estaria desenvolvendo "fielmente" sua função de mãe, de estar perto. Independente dos filhos serem pequenos ou adultos o importante para Eliane era traçar esse caminho e hoje segundo ela, isso reflete nos filhos, na concepção de mundo que seus filhos criaram. Seu filho, que hoje está estudando no ensino médio, já elaborou o que quer fazer quando acabar os estudos e sua filha, que está terminando o ensino médio, já tem em mente que quer prestar um vestibular e fazer um curso de graduação. Eliane acredita que de certa forma a sua trajetória influenciou na vida de seus filhos, por conta do que ela passou para que pudesse se formar. Durante 5 anos, saía de manhã de casa para trabalhar e chegava após as 23 horas em casa.

Durante a entrevista, Eliane relata que em sua família faltava uma herança familiar acadêmica: Ela é a única da família a entrar na graduação e se formar. Por ser a única que fez graduação, no início era 
visto pela família como a ovelha negra, a sem juízo, nunca compreendiam o porquê de estudar tanto, não aceitavam o fato de Eliane ter filhos e querer estudar, principalmente a sua mãe, pois apesar de ajudar sua filha, cuidando dos seus netos, ela tinha uma posição bem clara diante a situação: ela dizia que a função da mulher é cuidar dos filhos e do lar, não tem porque estudar sendo que tem filhos para criar.

\subsection{Casamento e maternidade: modelos rígidos de "ser mulher"}

Ser mulher perpassa por várias condições, que foram socialmente construídas há muitas décadas. No século XIX a diferença entre os sexos é retomada com a descoberta da biologia e medicina. Perrot (1988) diz que esse discurso naturalista, insiste na existência de duas "espécies" com qualidades e aptidões particulares. Aos homens o cérebro, a inteligência, a razão lúcida, a capacidade de decisão. Às mulheres, o coração, a sensibilidade, os sentimentos. Segundo a teórica feminista Tania Navarro Swain (2000), a história ocidental naturaliza as relações e funções atribuídas a homens e mulheres através da ideia de que o corpo biológico - natural está ligado com o papel social - cultural dos indivíduos, recriando-as e desenvolvendo uma política de esquecimento que apagar o plural e o múltiplo do humano, ou seja, a hierarquia social se baseia nas diferenças biológicas para se organizar. As mulheres na sociedade patriarcal estão reduzidas ao corpo, sexo e 
matriz, Simone de Beauvoir ${ }^{2}$ comentou que (...) "ela foi engendra na generalidade de seu corpo, não na singularidade de sua existência”, ou seja, sua famosa frase que é reproduzia o tempo topo "Não se nasce mulher, torna-se", sem dúvida define bem o que é ser mulher ou ser homem, pois os modelos de masculinidade e feminilidade são definidos pela sociedade, através da forma de se comportar, de falar, de vestir dentro dos parâmetros do patriarcado.

Segundo a lógica patriarcal, é como se o homem tivesse nascido para lidar das questões públicas, se envolverem com política, ter o poder. A mulher, pelo contrário é feita pela piedade e o interior. Foram entregue as mulheres os afazeres domésticos - dentro de certos limites, a família, a casa, o núcleo da esfera privada.

O casamento no século XIX era tido como o ápice na vida de uma mulher, ela deixava de pertencer ao pai e passava a pertencer ao seu marido, o qual tinha a função de representar a família, administrar os bens comuns e aqueles trazidos pela esposa e fixar o domicílio do casal. Prescrevia-se, ainda, que a mulher não podia trabalhar sem a permissão do marido e autorizava-se a que ele recorresse à força e violência masculina contra os "excessos femininos". Enfim, a ela, a esposa cabia a identidade doméstica; a ele, a pública, para desempenhar o papel de provedor da família (PRIORE, 2005, p. 245-246). Como

${ }^{2}$ BEAVOUIR, Simone de. O segundo sexo, volume II. Editora Difusão europeia do livro, 1967. 
ponderou Ana Silva Scott (2012, p. 16), "Na ordem patriarcal, a mulher devia obedecer a pai e marido, passando da autoridade de um para o outro através de um casamento monogâmico e indissolúvel. O domínio masculino era indiscutível".

Dentro dessa ordem patriarcal, a maternidade é um aspecto fundamental para que a mulher torna-se mulher 'de verdade', a fertilidade, o fato de procriar há faz uma boa esposa dentro dessa lógica. É para este aspecto que Maria de Fátima Araújo indica que:

O amor e o casamento, tal como o conhecemos hoje, surgiu com a ordem burguesa, mas só ganhou feição a partir do século XVIII, quando a sexualidade passou a ocupar um lugar importante dentro do casamento. $\mathrm{O}$ amor, no sentido moderno de consensualidade, escolha e paixão amorosa, não existia no casamento, sendo, em geral, vivenciado nas relações de adultério, e a sexualidade não era vivida como lugar de prazer, sua função específica, era a reprodução (ARAÚJO, 2002, p.2).

Ou seja, uma das principais funções da mulher dentro do casamento é a reprodução. Badinter (1980) em seu livro "Um amor conquistado: O mito materno", diz que:

A definição, carregada de pressupostos ideológicos, do Larousse do século XX (edição de 1971), que descreve o instinto materno como "uma tendência primordial que cria em toda mulher normal um desejo de maternidade e que, uma vez satisfeito esse 
desejo, incita a mulher a zelar pela proteção física e moral dos filhos", pois acredito que uma mulher pode ser "normal" sem ser mãe, e que toda mãe não tem uma pulsão irresistível a se ocupar do filho (BADINTER, 1980).

Nesse contexto percebemos que uma mulher que não tem o desejo de ser mãe, não é 'normal', não é mulher de verdade, ou seja, não está desempenhado o seu papel fundamental. Percebemos que até hoje, essa pressão que é feitas às mulheres sobre a maternidade continua forte, é como se as mulheres antes de qualquer coisa tivessem que pensar em ter filhos, cria-los, viver em função deles suas vontades, e profissão ficam em segundo plano, só se pode pensar nisso depois de assumido o papel de mãe.

Se Eliane pensasse nessa lógica, ela não teria feito graduação, pois quando entrou na faculdade já estava separada, seus filhos eram pequenos, trabalhava durante o dia enquanto seus filhos ficavam na creche. À noite, quando Eliane ia para a faculdade, seus filhos ficavam sob os cuidados da avó materna. Essa situação, segundo ela, era questionada com frequência pela sua mãe, na lógica desta, ela deveria ter feito alguma coisa para 'segurar o casamento' e manter a estrutura familiar intacta. Mas as circunstâncias e principalmente as decisões tomadas pela Eliane, fizeram que a história fosse diferente.

Para Eliane, toda essa dificuldade em se formar em Ciências Sociais, foi válida, hoje ela mantém sua casa através da graduação que 
fez, visualiza para o futuro uma perspectiva de vida melhor. Ela não pensa em parar de estudar.

\subsection{Pedagogia Feminista: uma ferramenta emancipatória?}

Historicamente, o processo educativo tem sido marcado por práticas que reforçam a educação sexista e o patriarcado. Mas para questionar essas práticas, a Pedagogia Feminista propõe uma reflexão e práticas voltadas para o empoderamento feminino e emancipação de mulheres, desconstruindo paradigmas que tendem a levá-las a submissão, inviabilizando suas práticas (LOURO 1997).

Essa metodologia de trabalho parte do pressuposto que vivemos em uma sociedade que reforça as diferenças de gênero, no qual as mulheres se encontram em um patamar inferior aos homens, o sistema capitalista reproduz essa lógica, no entanto, uma série de mudanças é necessária para reverter essa lógica, (mudanças no que tange a política, a cultura, a economia) a intencionalidade da Pedagogia Feminista é tornar as mulheres precursoras de suas próprias histórias através da educação. Essa metodologia questiona o dualismo que permeia as atuais relações entre homens e mulheres, como afirma Louro (1997, p. 112113):

A lógica subjacente a esta proposta se assenta em alguns dualismos "clássicos": 


\section{competição/cooperação:}

objetividade/subjetividade;ensino/aprendizagem;hier arquia/igualdade; - dualismo em que o primeiro termo representa o modelo androcêntrico de educação e o segundo termo aponta para a concepção feminista.

Propõe a valorização das vozes femininas, para Louro (1997), as situações de aprendizagens, são momentos privilegiados em que todas/os são levadas/os a construírem conhecimento de forma cooperativa, no entanto a Pedagogia Feminista pretende ser emancipatória, pois visa à conscientização, a libertação e a transformação das sujeitas e de sua realidade.

Nesse contexto, sem dúvida a educação torna-se uma ferramenta importante para que as mulheres tornem-se precursora de suas histórias e tenham perspectiva de uma vida para além das limitações que o patriarcado impõe. Como é o caso de Eliane, que após o término de seu casamento de 10 anos, voltou aos estudos, cursou uma graduação, está terminando uma pós-graduação e encontra-se em total independência financeira, e ainda por cima, mantêm uma filha e um filho. Ela própria, em seu depoimento afirma que sua vida é marcada por dois momentos: o primeiro é a vida de dona-de-casa, esposa, que se preocupava em fazer as vontades do marido, cuidar dos filhos: e um segundo momento; no qual ela se 'libertou' das amarras de um casamento que só reforçava 
o patriarcado, no qual sua voz, suas vontades estavam anuladas como indivíduo, como mulher.

Tendo como base os aspectos mencionados aqui, no que diz respeito à educação e a trajetória de vida das mulheres, o caso de Eliane nos possibilita pensar que as trajetórias de vida das mulheres, são modificadas conforme vão se inserindo no âmbito escolar, na graduação e essa inserção abre portas, podendo ocasionar em uma independência e um rompimento de padrões socialmente construídos.

\section{Referências:}

ARAÚJO, Maria de Fátima. Amor, casamento e sexualidade: velhas e novas configurações. V.22 n.2 Brasília jun. 2002.

BADINTER, Elizabeth. Um Amor Conquistado: O Mito do Amor Materno. Editora Nova Fronteira, 1980.

BEAVOUIR, Simone de. O segundo sexo, volume II. Editora Difusão europeia do livro, 1967.

BOURDIEU, Pierre. A Ilusão Biográfica. In: FERREIRA, Marieta de Morais, AMADO, Janaína (Org.) Usos e Abusos da História Oral. Rio de Janeiro: FGV, 1996.

HAHNER, June. A mulher no Brasil. Editora Civilização brasileira, Rio de Janeiro, 1978.

LOURO, Guacira Lopes. Gênero, Sexualidade e Educação: Uma perspectiva pós-estruturalista. Petrópolis - RJ, Vozes, 1997. 
PERROT, Michelle. Os excluídos da história: Operários, Mulheres, Prisioneiros. Ed. Paz e Terra, 1988.

PINSKY, Carla Bassanezzi; PEDRO, Joana Maria (Org.). Nova história das mulheres no Brasil. SP: Contexto, 2012.

PRIORE, Mary Del. História do amor no Brasil. SP: Contexto, 2005.

SCOTT, Ana Silva. O caleidoscópio dos arranjos familiares. In: Nova história das mulheres no Brasil. PINSKY, Carla Bassanezzi; PEDRO, Joana Maria (Org.). SP: Contexto, 2012.

SOIHET, R. Carmen Dolores: as contradições de uma literata da virada do século. La manzana de la discórdia, v. 4, p. 33-42, Dic. 2009. Disponível em: $<\mathrm{http} / / /$ manzanadiscordia.univalle.edu.co/volumenes/articulos/V4N2/art 4.pdf..>. Acesso em: abr.2013.

SWAIN, Tania Navarro. Feminismos: Teorias e perspectivas. Revista Textos de história da pós-graduação em História da UnB, vol.8, números 1-2, 2000.

YALOM, Marilyn. A história da esposa. Da virgem Maria a Madona. O papel da mulher casada dos tempos bíblicos até hoje. Rio de Janeiro: Ediouro, 2002. 